\title{
A phase 3, open-label, multicenter study of a 6-month pre-mixed depot formulation of leuprolide mesylate in advanced prostate cancer patients
}

\author{
Neal Shore ${ }^{1}$ (1) - Ivan Mincik ${ }^{2} \cdot$ Mark DeGuenther $^{3} \cdot$ Vladimir Student Jr. $^{4} \cdot$ Mindaugas Jievaltas $^{5}$. Jitka Patockova ${ }^{6}$. \\ Kelle Simpson ${ }^{6} \cdot$ Chu-Hsuan $\mathrm{Hu}^{6} \cdot$ Shih-Tsung Huang ${ }^{7} \cdot$ Yuhua $\mathrm{Li}^{8} \cdot$ Yisheng Lee $^{8} \cdot$ Ben Chien $^{8} \cdot \mathrm{John} \mathrm{Mao}^{8}$
}

Received: 11 January 2019 / Accepted: 25 March 2019 / Published online: 3 April 2019

(c) The Author(s) 2019

\begin{abstract}
Objectives To determine the safety, efficacy and pharmacokinetic (PK) profile of a pre-mixed depot formulation of leuprolide mesylate subcutaneous injectable suspension (LMIS) $50 \mathrm{mg}$ for up to 1 year of treatment for subjects with advanced prostate cancer.

Patients and methods In this open-label, multicenter study, prostate cancer patients with indication for androgen ablation therapy received two subcutaneous injection of LMIS $50 \mathrm{mg} 6$ months apart and were followed for an additional 6 months. Two efficacy primary end points were the percentage of subjects with a serum testosterone level $\leq 50 \mathrm{ng} / \mathrm{dL}$ by Day 28 as well as the percentage of subjects with similar testosterone suppression from Day 28 to Day 336.

Results Of the 137 enrolled subjects, 15 (10.9\%) subjects did not complete the study, including 5 subjects who terminated early due to an adverse event. By Day 28, 98.5\% (95\% confidence interval 94.8-99.8) of the subjects achieved a castrate testosterone level. At the end of the study, $97 \%$ and $95.9 \%$ of the subjects had serum testosterone level $\leq 50 \mathrm{ng} / \mathrm{dL}$ and $\leq 20 \mathrm{ng} /$ $\mathrm{dL}$, respectively. LMIS $50 \mathrm{mg}$ significantly reduced serum prostate-specific antigen levels after its first injection and this PSA declination effect remained until the end of the study. No statistically significant change was observed in worsening bone pain or urinary symptom assessments during the study. Hot flush (48.9\%) and hypertension (14.6\%) were the two most common adverse events reported.
\end{abstract}

Conclusions LMIS $50 \mathrm{mg}$, administered at 6-month intervals, effectively suppressed serum testosterone level, and demonstrated a consistent safety profile.

Keywords Prostate cancer · Leuprolide acetate $\cdot$ Luteinizing hormone-releasing hormone agonist $\cdot$ Testosterone $\cdot$ PSA . Androgen deprivation therapy

Neal Shore

nshore@gsuro.com

1 Carolina Urologic Research Center, Suite B, 823 82nd Parkway, Myrtle Beach, SC 29579, USA

2 Urocentrum Milab, s.r.o. Hollého 14/D, 08001 Presov, Slovak Republic

3 Urology Center of Alabama, 3485 Independence Drive, Homewood, AL 35209, USA

4 Fakultní Nemocnice Olomouc Urologická Klinika, I. P. Pavlova 6, Olomouc 779 00, Czech Republic
5 Hospital of Lithuanian University of Health Sciences Kauno Klinikos, Eiveniu 2, Kaunas 50009, Lithuania

6 QPS Holdings, LLC, Three Innovation Way, Suite 240, Newark, DE 19711, USA

7 Department of Surgery and Urology, Chang Gung Memorial Hospital-Linkou, Chung Gung University, College of Medicine, Taoyuan, Taiwan

8 Foresee Pharmaceuticals Co., Ltd., 3 F, No 19-3, Sanchong Road, NanKang Dist., Taipei 11501, Taiwan, R.O.C. 


\section{Introduction}

In 2018, the American Cancer Society estimates that prostate cancer is the most frequently diagnosed cancer and the second cause of cancer-related death for men in the US [1]. In the majority of these cases, the growth, proliferation and survival of prostate cancer cells are dependent upon androgen stimulation, predominantly via testosterone and dihydrotestosterone, produced within the Leydig cells of the testes [2]. Since the benefits of surgical castration on the outcomes of metastatic prostate cancer were first described in 1941 [3], androgen ablation remains the mainstay of treatment for men with advanced prostate cancer [4].

Pharmacologic LHRH drug development over the years demonstrated that chronic administration of synthetic long-acting analogs of the luteinizing hormone-releasing hormone (LH-RH) resulted in suppression of Leydig cell function, leading to the first use of these agents in the treatment of prostate cancer [5]. LH-RH analogs long-term administration eventually reduces the number of LH-RH receptors and inhibits gonadotropin synthesis and secretion $[6,7]$. Within weeks of treatment, prostate cancer patients receiving LH-RH analogs exhibit suppression of serum testosterone level, similar to surgical castration [8]. Prostate cell division and growth are dependent on testosterone, and less testosterone results in more apoptotic cells in prostate; this is most important in the systemic treatment of prostate cancer.

Over the following decades, androgen ablation with LH-RH analogs has proven its clinical equivalence to bilateral orchiectomy [9], with the potential advantages of avoiding the irreversibility and adverse psychological effects of surgical castration [10] and also potentially allowing the intermittent administration of androgen suppression, if clinically indicated [11-13]. Several different LH-RH analogs were developed, studied and approved for the treatment of prostate cancer, including leuprolide, triptorelin, goserelin, histrelin and buserelin. These drugs may be administered as 1-, 3-, 4- or 6-month intramuscular or subcutaneous injections, or as a 12 -month subcutaneous implant [14].

More recently, the leuprolide mesylate injectable suspension (LMIS) was developed as a pre-mixed drug product containing $50 \mathrm{mg}$ leuprolide mesylate (equivalent to $42 \mathrm{mg}$ of leuprolide free base) formulated in a solution of $\mathrm{N}$-methyl-2-pyrrolidone and poly (D,L-lactide) to control and sustain the release of leuprolide over a 6-month period after subcutaneous administration. In addition to the convenience of clinical use, LMIS $50 \mathrm{mg}$ was developed as a single, sterile, pre-filled syringe which is ready to use and does not require premixing prior to subcutaneous injection, thus eliminating a potential source of error which has been shown to affect the clinical efficacy of drug administration [15].

The present study was designed to determine the safety, tolerability, and efficacy of LMIS $50 \mathrm{mg}$ for up to 1 year of exposure in subjects with advanced prostate carcinoma, as well as to evaluate the pharmacokinetic (PK) behavior of $50 \mathrm{mg}$ LMIS following two separate subcutaneous injections given 6 months apart.

\section{Patients and methods}

\section{Study design and patients}

This was a multi-center, open-label, single-arm study conducted to assess the safety, efficacy and PK behavior of LMIS $50 \mathrm{mg}$ in subjects with prostate cancer.

Eligible patients were age $\geq 18$ years, had histologically confirmed prostate carcinoma, baseline morning serum testosterone level $>150 \mathrm{ng} / \mathrm{dL}$, Eastern Cooperative Oncology Group (ECOG) performance status $\leq 2$, adequate organ function, and were assessed by the physician investigator to be candidates for androgen ablation therapy. Patients who failed primary treatment (surgery/radiation) are still eligible.

Key exclusion criteria included concomitant use of chemotherapy, immunotherapy, cryotherapy, radiotherapy, or anti-androgen therapy, or within the previous 8 weeks, for treatment of carcinoma of the prostate; utilization of any LH-RH suppressive therapy within the previous 6 months; history of anaphylaxis or contraindication to any $\mathrm{LH}-\mathrm{RH}$ analogs; clinical evidence of or risk for urinary obstruction; clinically significant abnormal electrocardiogram (ECG) and/or history of clinically significant cardiovascular disease; use of 5-alpha reductase inhibitor within the last 6 months; history or the presence of insulin-dependent diabetes mellitus (type I; the presence of well-controlled diabetes mellitus type II was allowed if only oral hypoglycemic was required); and use of systemic corticosteroids at a dose $>10 \mathrm{mg} /$ day.

Part I was conducted to establish the safety of LMIS $50 \mathrm{mg}$ with more frequent visits for safety monitoring. Patients received a single subcutaneous injection of LMIS $50 \mathrm{mg}$ every 6 months (over the course of 2 doses on Day 1 and Day 168). The first 10 (of the 33) subjects served as a "sentinel" group for safety purposes and the Independent Data Monitoring Committee conducted interim safety reviews for these subjects at the end of Week 2, Month 1, Month 3, and Month 6. These four interim safety reviews were performed in addition to the interim review of safety data, serum leuprolide concentrations, and serum testosterone suppression status scheduled for the first 30 subjects following their Day 28 assessments in Part I. 
If $\geq 90 \%$ of Part I subjects (i.e., $\geq 27$ of the 30 subjects) achieved suppression of serum testosterone to castrated levels within 1 month of the initial dose and demonstrated acceptable safety and tolerability, Part II of the study was opened to enroll approximately 100 subjects. After the second administration of LMIS $50 \mathrm{mg}$, all subjects were followed for safety, tolerability, efficacy, PK, and ancillary clinical and laboratory markers for an additional 6 months.

\section{Outcomes}

The primary efficacy end points were the percentage of subjects with a serum testosterone $\leq 50 \mathrm{ng} / \mathrm{dL}$ (castration level) by Day $28 \pm 1$ (i.e., within 28 days following the first injection of investigational product) and the percentage of subjects with testosterone suppression $(\leq 50 \mathrm{ng} / \mathrm{dL})$ from Day 28 through Day 336. Insufficient suppression of testosterone was defined as suppression that did not occur by Day 28 or the occurrence of a testosterone level $>50 \mathrm{ng} / \mathrm{dL}$ between Day 28 and Day 336.

The efficacy of two separate doses of LMIS $50 \mathrm{mg}$ was further analyzed by examining the percentage of subjects with the serum testosterone $\leq 20 \mathrm{ng} / \mathrm{dL}$ on Day 28 and Day 336.

Secondary end points included the proportion of subjects exhibiting post-suppression excursion of serum testosterone to $>50 \mathrm{ng} / \mathrm{dL}$, either through "breakthrough" (i.e., episodes unrelated to LMIS $50 \mathrm{mg}$ dosing), or through the "acuteon-chronic" effect (i.e., related to the second dose of LMIS $50 \mathrm{mg}$ ), which is commonly referred to as "surge".

Secondary end points also included the effect of LMIS $50 \mathrm{mg}$ on serum prostate-specific antigen (PSA) levels, serum LH levels, laboratory parameters, local skin tolerability, bone pain and urinary symptom exacerbations. The PK behavior of leuprolide was evaluated by full PK profiles from serum leuprolide concentrations in Part I subjects. Additional serum leuprolide concentration data were collected during Part II.

\section{Assessments}

Pharmacokinetic (PK) and pharmacodynamics (PD) assessments of serum leuprolide concentrations and serum testosterone concentrations using a validated LC/MS/MS bioanalytical methods were performed at the bioanalytical laboratory. The PK parameters, including $C_{\max }, T_{\max }, C_{\mathrm{wk} 4}$, $C_{\text {mon6 }}, \mathrm{AUC}_{0-4 \mathrm{wk}}, \mathrm{AUC}_{0-6 \mathrm{mon}}$ and $C_{\text {avg }}(0-6$ months), were determined using non-compartmental approaches using Phoenix WinNonlin ${ }^{\circledR}$ (Certara USA, Inc., Princeton, NJ, USA).

The safety and tolerability of LMIS $50 \mathrm{mg}$ were evaluated by analyzing adverse events by changes in: bone pain; urinary symptoms measurements by the AUA symptom score and by the Visual Analog Scale (VAS) scale; vital signs; physical examinations; laboratory tests; and 12-lead resting ECGs. Additional assessments were performed for local skin tolerability.

\section{Statistical analysis}

The intention-to-treat (ITT) population was defined as any subject who received at least one dose of LMIS $50 \mathrm{mg}$ and the per protocol (PP) population was defined as any subject who received two doses of LMIS $50 \mathrm{mg}$, followed the inclusion/exclusion requirements of the protocol, and had no major protocol violation. The ITT and PP populations were used in the efficacy analyses. Any subject receiving a dose of LMIS $50 \mathrm{mg}$ was included in the safety analysis.

For primary efficacy end points, the percentage of subjects with a serum testosterone $\leq 50 \mathrm{ng} / \mathrm{dL}$ (castrate level) by Day $28 \pm 1$ (day) was analyzed using a standard large sample approximation to a Binomial distribution. The percentage of subjects with testosterone suppression $(\leq 50 \mathrm{ng} / \mathrm{dL})$ from Day 28 to Day 336 was analyzed using a Kaplan-Meier approach, in which an event was defined as the occurrence in any subject with a serum testosterone level $>50 \mathrm{ng} / \mathrm{dL}$ at or before Day 336. The duration of time to an event was summarized by Kaplan-Meier plot, and presented as event number, percentage, $95 \%$ confidence interval (CI) for percentage, mean, median and $95 \%$ CI for median.

For descriptive statistics, continuous variables were presented as number of observations, mean, standard deviation, median, range, Hodges-Lehmann estimator and 95\% CI. Categorical variables were presented by frequency and percentage. Changes from baseline were tested by a paired $t$ test or Wilcoxon signed-rank test for continuous variables using a significance level of 0.05 .

\section{Results}

A total of 137 subjects were enrolled in this study, including 33 subjects in Part I and 104 subjects in Part II. Of the 137 enrolled subjects, 15 (10.9\%) subjects did not complete the study, including 5 subjects who terminated early due to adverse event (Fig. 1). The median age of the entire cohort was 71.0 years and the median duration with diagnosed prostate carcinoma was 633 days. Almost $90 \%$ of enrolled subjects were Caucasian. Other baseline characteristics are detailed in Table 1.

\section{Primary efficacy end points}

The percentage of subjects with a serum testosterone $\leq 50 \mathrm{ng} / \mathrm{dL}$ (castrate level) by Day 28 was $98.5 \%$ (95\% 


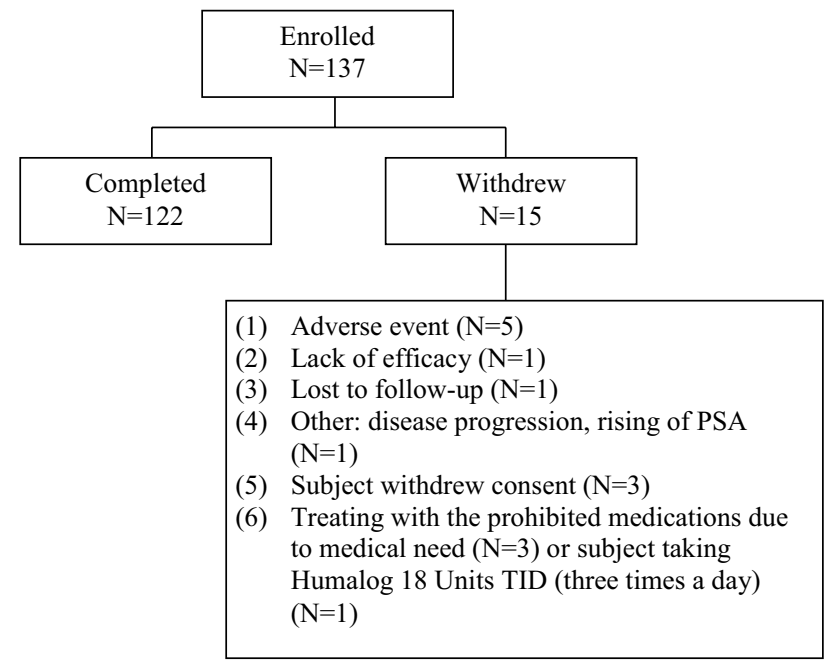

Fig. 1 Disposition of patients

Table 1 Baseline characteristics

\begin{tabular}{lccc}
\hline Variable & Part I $(N=33)$ & Part II $(N=104)$ & Total $(N=137)$ \\
\hline $\begin{array}{l}\text { Age (years) } \\
\text { Median }\end{array}$ & & & \\
$\quad$ (range) & & & \\
Race & & & \\
White & $25(75.8 \%)$ & $98(94.2 \%)$ & $123(89.8 \%)$ \\
Black & $4(12.1 \%)$ & $4(3.8 \%)$ & $8(5.8 \%)$ \\
Asian & $4(12.1 \%)$ & $1(1.0 \%)$ & $5(3.6 \%)$ \\
Unknown & $0(0.0 \%)$ & $1(1.0 \%)$ & $1(0.7 \%)$ \\
Diagnosis (days) & & & \\
Median & $2254.0(12-$ & $158.5(0-13,290)$ & 633.0 \\
$\quad$ range) & $9066)$ & & $(0-13,290)$ \\
Staging & & & \\
I & $1(3.0 \%)$ & $3(2.9 \%)$ & $4(2.9 \%)$ \\
II & $8(24.2 \%)$ & $23(22.1 \%)$ & $31(22.6 \%)$ \\
III & $5(15.2 \%)$ & $32(30.8 \%)$ & $37(27.0 \%)$ \\
IV & $9(27.3 \%)$ & $23(22.1 \%)$ & $32(23.4 \%)$ \\
Unknown & $10(30.3 \%)$ & $23(22.1 \%)$ & $33(24.1 \%)$ \\
ECOG performance status & & \\
0 & $30(90.9 \%)$ & $84(80.8 \%)$ & $114(83.2 \%)$ \\
1 & $3(9.1 \%)$ & $19(18.3 \%)$ & $22(16.1 \%)$ \\
2 & $0(0.0 \%)$ & $1(1.0 \%)$ & $1(0.7 \%)$ \\
\hline
\end{tabular}

CI, 94.8-99.8) in the ITT population and 99.2\% (95\% CI 95.6-100.0) in the PP population, respectively.

The percentage of subjects with testosterone suppression $(\leq 50 \mathrm{ng} / \mathrm{dL})$ from Day 28 to Day 336 was $97.0 \%$ (95\% CI 92.2-98.9) in the ITT population and $97.6 \%$ (95\% CI 92.7-99.2) in the PP population, respectively. The mean serum testosterone was below $\leq 50 \mathrm{ng} / \mathrm{dL}$ at

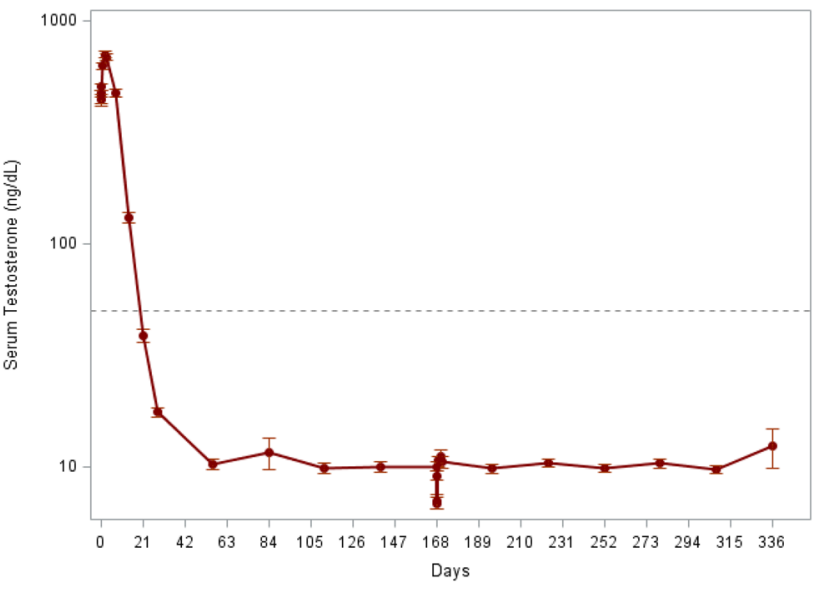

Fig. 2 Mean serum testosterone over time in the ITT population

$38.96 \pm 30.18 \mathrm{ng} / \mathrm{dL}$ at Day 21 and remained below castration levels at $12.38 \pm 28.21 \mathrm{ng} / \mathrm{dL}$ at Day 336 in the ITT population (Fig. 2).

Of 135 subjects who achieved the castrated level serum testosterone $(\leq 50 \mathrm{ng} / \mathrm{dL}), 95$ subjects $(95 / 135,70.4 \%)$ achieved serum testosterone level $<20 \mathrm{ng} / \mathrm{dL}$ on Day 28. On Day 336, all subjects who completed the study $(122 / 122)$ achieved castrated serum testosterone level ( $\leq 50 \mathrm{ng} / \mathrm{dL})$, among which 117 subjects $(117 / 122,95.9 \%)$ achieved serum testosterone level $<20 \mathrm{ng} / \mathrm{dL}$.

\section{Secondary efficacy end points}

Only two subjects $(2 / 137,1.5 \%)$ exhibited post-suppression elevations of serum testosterone to $>50 \mathrm{ng} / \mathrm{dL}$ after reaching castrate level of testosterone on Day 28. One was on Days 169-171, and the other was on Day 170. These transient elevations of serum testosterone levels were observed following the second administration of LMIS $50 \mathrm{mg}$ on Day 168 and possibly related to the acute-onchronic effect of LH. Both subjects had their serum testosterone levels below the castrate levels by the end of the study (Day 336). Besides these episodes, no other "breakthrough" episode of serum testosterone to $>50 \mathrm{ng} / \mathrm{dL}$ was observed in this study.

The administration of LMIS $50 \mathrm{mg}$ significantly reduced the serum PSA levels after its first injection and this effect remained until the end of the study. In a post hoc analysis of the 99 subjects who had elevated PSA (>4 ng/ $\mathrm{mL}$ ) at baseline, more than $90 \%$ subjects experienced a decrease in PSA levels on Day 28. The percentages of subjects with elevated PSA levels at baseline decreased by LMIS $50 \mathrm{mg}$ injection in different visits are summarized in Table 2. 
Table 2 Summary of PSA levels over time for subjects with elevated PSA at baseline (ITT population)

\begin{tabular}{|c|c|c|c|c|c|c|c|c|}
\hline \multirow[t]{3}{*}{ Visit } & \multicolumn{8}{|c|}{ ITT population $(N=99)$} \\
\hline & \multicolumn{8}{|c|}{ Number of patients (percent) } \\
\hline & $n$ & $<50 \%$ decrease & 50 to $<90 \%$ decrease & 90 to $<95 \%$ decrease & $\geq 95 \%$ decrease & Increase & $\leq 4 \mathrm{ng} / \mathrm{mL}$ & $>4 \mathrm{ng} / \mathrm{mL}$ \\
\hline Day 28 & 99 & $26(26.3 \%)$ & $65(65.7 \%)$ & $4(4.0 \%)$ & $1(1.0 \%)$ & $3(3.0 \%)$ & $47(47.5 \%)$ & $52(52.5 \%)$ \\
\hline Day 84 & 98 & $4(4.1 \%)$ & $31(31.6 \%)$ & $22(22.4 \%)$ & $41(41.8 \%)$ & $0(0.0 \%)$ & $75(76.5 \%)$ & $23(23.5 \%)$ \\
\hline Day 168 & 94 & $2(2.1 \%)$ & $24(25.5 \%)$ & $11(11.7 \%)$ & $57(60.6 \%)$ & $0(0.0 \%)$ & $80(85.1 \%)$ & $14(14.9 \%)$ \\
\hline Day 252 & 90 & $2(2.2 \%)$ & $16(17.8 \%)$ & $13(14.4 \%)$ & $58(64.4 \%)$ & $1(1.1 \%)$ & $76(84.4 \%)$ & $14(15.6 \%)$ \\
\hline Day 336 & 88 & $4(4.5 \%)$ & $17(19.3 \%)$ & $11(12.5 \%)$ & $55(62.5 \%)$ & $1(1.1 \%)$ & $76(86.4 \%)$ & $12(13.6 \%)$ \\
\hline
\end{tabular}

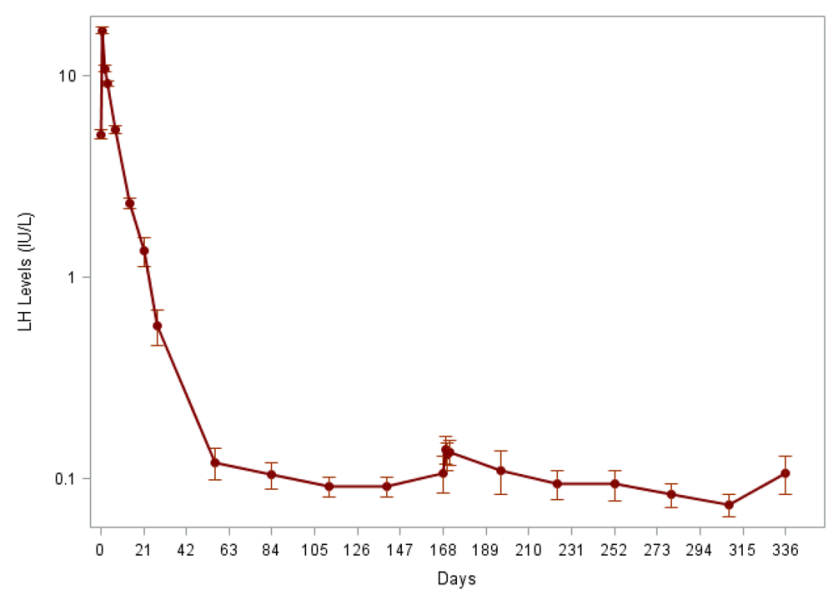

Fig. 3 Mean LH levels over time from the local laboratory in the ITT population

In the ITT population, the mean LH level at baseline was $5.13 \pm 3.04 \mathrm{IU} / \mathrm{L}$ and, as expected, an acute increase of mean serum LH level on Day 1 was observed after the first administration of LMIS $50 \mathrm{mg}$. A rapid decrease of serum LH levels was observed on Days 2 and 3 until it approached a plateau on Day 140. A slight increase in mean LH level was observed at the end of the study on Day 336 (Fig. 3).

\section{Safety}

A total of 553 AEs from 114 subjects (114/137, 83.2\%) were reported with at least one treatment-emergent adverse events (TEAEs) occurrence in this study (Table 3). The most common ( $\geq 5 \%$ ) TEAEs observed was hot flush $(48.9 \%)$, followed by hypertension (14.6\%), pain in extremity $(9.5 \%)$, injection site pain $(7.3 \%)$, arthralgia $(6.6 \%)$, fatigue $(6.6 \%)$, nocturia $(5.8 \%)$, back pain $(5.1 \%)$ and nasopharyngitis $(5.1 \%)$. With regard to the severity of TEAEs, most were mild or moderate.
Of 137 enrolled subjects, 62\% subjects (85/137) were reported with drug-related AEs determined by investigators. The most common ( $\geq 5 \%$ ) drug-related AEs observed were hot flush $(48.2 \%)$, followed by injection site pain $(7.3 \%)$ and fatigue $(5.8 \%)$.

Five out of 137 subjects $(3.6 \%)$ who experienced an adverse event (AE) discontinued from the study prematurely. These AEs included: acute kidney injury, atrial fibrillation, cerebrovascular accident, death, hormonerefractory prostate cancer, and prostate cancer metastatic. None of these AEs were determined to be related to the administration of $50 \mathrm{mg}$ LMIS.

Of 34 serious AEs, only three were determined as related to the investigational product by the primary investigators, and agreed by the chief medical director of third-party CRO (QPS Holdings, LLC) which is conducting the clinical trial. The funder Foresee Pharmaceuticals played no role in such determination. These included blurred vision, left hip fracture, and myocardial infarction.

\section{Patient-reported outcomes}

The average change in degree of bone pain from baseline was $0.07 \pm 1.666$ on Day 168 and $0.24 \pm 1.988$ on Day 336 . The average change in degree of urinary pain from baseline was $-0.07 \pm 0.847$ on Day 168 and $0.09 \pm 1.280$ on Day 336. None of these differences was statistically significant.

Of the 137 subjects, approximately 68.6\% (94/137) felt satisfied [answered quality of life (QoL) questionnaire with 0 -delighted, 1 - pleased, or 2-mostly satisfied] with their lives at current condition at baseline. The respective figures on Day 168 and Day 336 were 69.7\% (90/129) and 65.9\% (87/132), indicating that the administration of LMIS $50 \mathrm{mg}$ did not appear to cause additional discomfort in subjects during the study.

\section{Pharmacokinetics}

The PK profiles of LMIS $50 \mathrm{mg}$ exhibited two phases. After dosing, an initial rapid increase of serum leuprolide 
Table 3 Summary of AEs (safety population)

\begin{tabular}{|c|c|c|c|c|c|c|c|c|c|}
\hline \multirow[t]{2}{*}{ Variables\status } & \multicolumn{3}{|c|}{ Part I $(N=33)$} & \multicolumn{3}{|c|}{ Part II $(N=104)$} & \multicolumn{3}{|c|}{ Total $(N=137)$} \\
\hline & Event & Subject & $(\%)$ & Event & Subject & $(\%)$ & Event & Subject & $(\%)$ \\
\hline \multicolumn{10}{|l|}{ TEAEs } \\
\hline Total & 160 & 31 & 93.9 & 393 & 83 & 79.8 & 553 & 114 & 83.2 \\
\hline \multicolumn{10}{|l|}{ TEAEs by severity } \\
\hline Mild & 116 & 29 & 87.9 & 279 & 76 & 73.1 & 395 & 105 & 76.6 \\
\hline Moderate & 36 & 19 & 57.6 & 94 & 40 & 38.5 & 130 & 59 & 43.1 \\
\hline Severe & 6 & 5 & 15.2 & 18 & 13 & 12.5 & 24 & 18 & 13.1 \\
\hline Hot flush & 18 & 18 & 54.5 & 51 & 49 & 47.1 & 69 & 67 & 48.9 \\
\hline Hypertension & 2 & 2 & 6.1 & 21 & 18 & 17.3 & 23 & 20 & 14.6 \\
\hline Pain in extremity & 3 & 2 & 6.1 & 15 & 11 & 10.6 & 18 & 13 & 9.5 \\
\hline Injection site pain & 6 & 5 & 15.2 & 7 & 5 & 4.8 & 13 & 10 & 7.3 \\
\hline Arthralgia & 5 & 4 & 12.1 & 6 & 5 & 4.8 & 11 & 9 & 6.6 \\
\hline Fatigue & 3 & 3 & 9.1 & 7 & 6 & 5.8 & 10 & 6 & 6.6 \\
\hline Nocturia & 1 & 1 & 3.0 & 8 & 7 & 6.7 & 9 & 8 & 5.8 \\
\hline Back pain & 4 & 4 & 12.1 & 3 & 3 & 2.9 & 7 & 7 & 5.1 \\
\hline \multicolumn{10}{|l|}{ Drug-related AEs } \\
\hline Total & 44 & 21 & 63.6 & 100 & 64 & 61.5 & 144 & 85 & 62.0 \\
\hline \multicolumn{10}{|c|}{ Drug-related AEs by severity } \\
\hline Mild & 35 & 19 & 57.6 & 81 & 56 & 53.8 & 116 & 75 & 54.7 \\
\hline Moderate & 7 & 5 & 15.2 & 18 & 13 & 12.5 & 25 & 18 & 13.1 \\
\hline Severe & 2 & 2 & 6.1 & 1 & 1 & 1.0 & 3 & 3 & 2.2 \\
\hline Hot flush & 18 & 18 & 54.5 & 50 & 48 & 46.2 & 68 & 66 & 48.2 \\
\hline Injection site pain & 6 & 5 & 15.2 & 7 & 5 & 4.8 & 13 & 10 & 7.3 \\
\hline Fatigue & 2 & 2 & 6.1 & 6 & 6 & 5.8 & 8 & 8 & 5.8 \\
\hline
\end{tabular}

concentration was observed, followed by a rapid decline over the first 3 days post-dose. The initial rapid increase was characterized by mean high serum concentrations ( $>90 \mathrm{ng} / \mathrm{mL})$, and the mean serum leuprolide levels maintained relatively constant over the majority of each 6-month dosing interval. Leuprolide appeared to be released continuously by the third day after dosing with steady serum concentrations ("plateau" phase) through the 6-month dosing interval (mean concentration: $0.370-2.97 \mathrm{ng} / \mathrm{mL}$ ). The serum leuprolide concentrations and the associated pharmacokinetics following the first and second doses of LMIS $50 \mathrm{mg}$ were similar, which suggested lack of significant accumulation with repeated dosing at 6-month intervals. The PK parameters following first and second dose administrations in Part I and Part II studies are summarized in Table 4.

\section{Limitations}

This study is an open-label, single-arm study design and no direct safety and efficacy comparisons to reference drug can be done. The study duration was 12 months and two injections with 6 months apart were given in these prostate cancer subjects. 30 subjects were given additional two injections in an extension safety study (total observation 24 months) that showed no evidence of safety and tolerability concerns. Thus, there is no long-term safety or efficacy data beyond 24 months available at this point.

\section{Discussion}

The phase 3 trial results show that the first injection of LMIS $50 \mathrm{mg}$ was effective in achieving testosterone suppression to castrate levels ( $\leq 50 \mathrm{ng} / \mathrm{dL}$ ) by Day 28 in $98 \%$ of subjects in this study, and that two doses of LMIS $50 \mathrm{mg}$ (6 months apart) successfully suppressed the serum testosterone to castrate levels in $97 \%$ of total subjects at the end of the study (approximately 1 year). Using a more stringent criterion for castration [16], 95.9\% of the patients had serum testosterone level $<20 \mathrm{ng} / \mathrm{dL}$ at the end of the study.

Although two subjects exhibited the post-suppression excursion of serum testosterone to $>50 \mathrm{ng} / \mathrm{dL}$ after achieving the castration level of testosterone on Day 28, which was presumably due to the acute-on-chronic surge following the second administration of LMIS $50 \mathrm{mg}$, the percentage of subjects exhibiting post-suppression elevation of serum testosterone to $>50 \mathrm{ng} / \mathrm{dL}$ was $0 \%$ in both ITT and PP populations at the end of the study. 


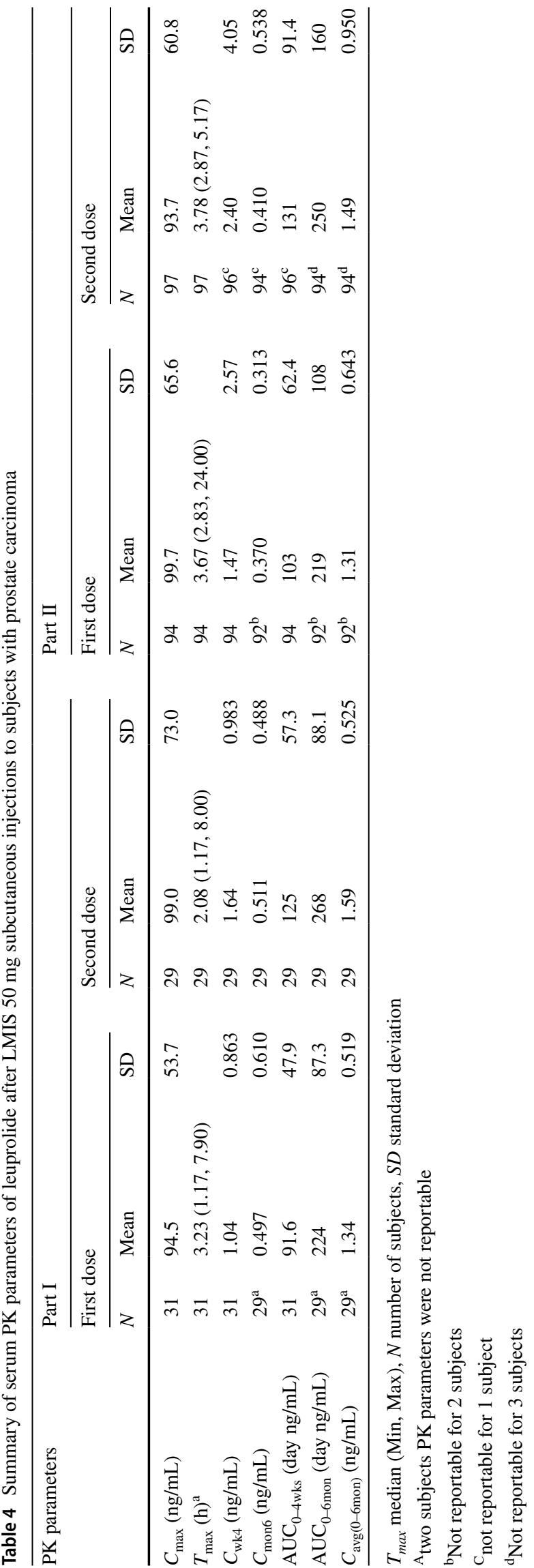

Recognizing the caveats of cross-study comparisons [17], LMIS $50 \mathrm{mg}$ demonstrated similar efficacy to other LH-RH agonists that are administered once every 6 months for reducing and maintaining the serum testosterone to castration levels during the study period (Table 5). Overall, the incidence of drug-related AEs after the administration of LMIS $50 \mathrm{mg}$ in the present study was also comparable to the incidence of drug-related AEs for similarly approved LH-RH analogs $[8,18]$, typically hot flush being the most frequent adverse event. Furthermore, the administration did not cause any additional unexpected adverse events for this class of drug administered for this patient population.

With regard to PK, LMIS $50 \mathrm{mg}$ resulted in a multiphasic leuprolide concentration versus time profiles characterized by a distinctive burst phase and a plateau phase. The initial acute increase of leuprolide mesylate concentration, followed by the rapid decline to a steadystate level, was similar to the release pattern seen with the other leuprolide depot formulations. After an initial burst phase characterized by mean high serum leuprolide concentrations (>90 ng/mL), mean serum leuprolide levels maintained relatively constant over the majority of each 6-month dosing interval. The serum leuprolide concentrations and the associated pharmacokinetics following the first and second doses of LMIS $50 \mathrm{mg}$ suggested lack of significant accumulation with repeated dosing at 6-month intervals.

LMIS $50 \mathrm{mg}$ was developed as a pre-filled, ready-to-use syringe that does not require reconstitution prior to subcutaneous injection. Adequate reconstitution of LH-RH ana$\log$ s is essential for the administration of products that do require premixing, to safeguard optimal and effective treatment of prostate cancer patients. Since preparation errors have been reported which have been associated with lack of drug efficacy, including increase of testosterone levels above the castrate level and/or increase of PSA levels [15], eliminating this administrative step could, thus, decrease a potential source of iatrogenic therapeutic inefficiency for the treatment of prostate cancer patients.

In conclusion, LMIS $50 \mathrm{mg}$ achieved the therapeutic goal of suppressing the serum testosterone to the castration level in $98 \%$ subjects on Day 28 and the suppression rate was maintained in $97 \%$ of the subjects throughout end of this study. Two separate doses of LMIS $50 \mathrm{mg}$ administered 6 months apart over a 12-month interval demonstrated similar safety and PK profile when compared to marketed products for the treatment of advanced prostate cancer patients, with the associated advantage of eliminating the need for manual reconstitution. 
Table 5 Cross-study comparison of efficacy end points between LMIS $50 \mathrm{mg}$ and two approved 6-month depot formulations of leuprolide acetate $(8,18)$

\begin{tabular}{|c|c|c|c|}
\hline Efficacy and safety assessment & LMIS $50 \mathrm{mg}$ & $\begin{array}{l}\text { 6-month subcutaneous depot } \\
\text { of leuprolide acetate } 45 \mathrm{mg} \\
\text { (8) }\end{array}$ & $\begin{array}{l}\text { 6-month intramuscular depot } \\
\text { of leuprolide acetate } 45 \mathrm{mg} \\
\text { (18) }\end{array}$ \\
\hline Total number of enrolled subjects & 137 & 111 & 151 \\
\hline Number of subjects in PP population & 124 & 109 & 148 \\
\hline Mean testosterone level at baseline (ng/dL) (PP population) & 475.2 & 367.7 & 435 \\
\hline Mean testosterone level on Day 2 (ng/dL) (PP population) & $695.7^{\mathrm{a}}$ & 588.6 & 608 \\
\hline Mean testosterone level on Day 28 (ng/dL) (PP population) & 17.4 & 16.7 & $<16$ \\
\hline Mean testosterone level on Day 336 (ng/dL) (PP population) & 9.95 & 12.6 & NA \\
\hline $\begin{array}{l}\text { Percentage of subjects reached serum testosterone castration } \\
\text { level ( }<50 \mathrm{ng} / \mathrm{dL}) \text { on Day } 28 \text { (PP population) }\end{array}$ & $99.2(123 / 124)$ & $99.1(108 / 109)$ & $99.3(147 / 148)$ \\
\hline $\begin{array}{l}\text { Percentage of total subjects with failed suppression of serum } \\
\text { testosterone to castrate levels (any testosterone value }>50 \mathrm{ng} / \\
\text { dL, including breakthrough and acute-on-chronic) (PP popu- } \\
\text { lation) }\end{array}$ & $2.4(3 / 124)$ & $1.8(2 / 109)$ & $6.08(9 / 148)$ \\
\hline $\begin{array}{l}\text { Percentage of subjects reached serum testosterone castrate level } \\
(<50 \mathrm{ng} / \mathrm{dL}) \text { from Day } 28 \text { to Day } 336 \text { (PP population) }\end{array}$ & $97.6(121 / 124)$ & $99(102 / 103)$ & $93.4(138 / 148)$ \\
\hline
\end{tabular}

a 8 h post dosing

Acknowledgements This study was funded by Foresee Pharmaceuticals Co., Ltd. (Taipei City, Taiwan). The funder, in collaboration with the investigators and authors of this study, contributed to study design. Clinical trial was conducted by the CRO (QPS Holdings LLC) with collaboration of Primary Investigators in protocol implementation, data collection, data analysis, and data interpretation. All authors had full access to the trial data. Editorial assistance for writing of the report was funded by Foresee. All authors were involved in the development and approval of the manuscript, and the corresponding author had final responsibility for the decision to submit for publication.

Author contributions NS: data collection/management, manuscript writing/editing. IM: data collection/management, manuscript editing. MDG: data collection/management, manuscript editing. VS: data collection/management, manuscript editing. MJ: data collection/management, manuscript editing. JP: protocol/project development, data collection and management, data analysis, manuscript editing. KS: data collection/management, manuscript editing. $\mathrm{CHH}$ : protocol/project development, data collection/management, data analysis, manuscript writing/editing. STH: protocol/project development, data collection/ management, data analysis, manuscript writing/editing. YL: protocol/ project development, manuscript editing. YL: data analysis, manuscript writing/editing. BC: protocol/project development, data analysis, manuscript editing. JM: protocol/project development, data collection/ management, data analysis, manuscript editing

\section{Compliance with ethical standards}

Conflict of Interest Neal Shore has no conflicts of interest to disclose. Ivan Mincik has no conflicts of interest to disclose. Mark DeGuenther has no conflicts of interest to disclose. Vladimir Student Jr has no conflicts of interests to disclose. Mingdaugas Jievaltas has no conflicts of interest to disclose. Jitka Patockova reports personal fees from QPS Holdings as a medical monitor for QPS Holdings, LLC which is the
CRO for the published study. Kelle Simpson reports personal fees as a project manager for QPS Holdings, LLC which is the CRO for the published study. Yisheng Lee reports personal fees from Foresee Pharmaceuticals during the study; as the chief medical officer for Foresee Pharmaceuticals, LLC which is the sponsor for the published study. Ben Chien reports personal fees from Foresee Pharmaceuticals as a President and CEO for Foresee Pharmaceuticals, LLC which is the sponsor for the published study. Chu-Hsuan $\mathrm{Hu}$ reports personal fees from QPS Holdings, LLC as and chief statistician for QPS Holdings, LLC which is the CRO for the published study. Shih-Tsung Huang reports personal fees from QPS Holdings LLD as chief medical officer for QPS Holdings, LLC which is the CRO for the published study. Yuhua Li reports personal fees from Foresee Pharmaceuticals, as vice president and chief manager for SIF technology for Foresee Pharmaceuticals, LLC which is the sponsor for the published study. John Mao reports personal fees from Foresee Pharmaceuticals as Vice president and chief manager for product development for Foresee Pharmaceuticals, LLC which is the sponsor for the published study.

Informed consent A properly executed written informed consent was obtained from each subject prior to the enrollment into the study and prior to the performance of any procedure related to the study.

Ethical standards All procedures performed in the study involving human participants was in accordance with the ethical standards of the institutional and ICH-GCP and with the 1964 Helsinki declaration and its later amendments or comparable ethical standards.

Open Access This article is distributed under the terms of the Creative Commons Attribution 4.0 International License (http://creativeco mmons.org/licenses/by/4.0/), which permits unrestricted use, distribution, and reproduction in any medium, provided you give appropriate credit to the original author(s) and the source, provide a link to the Creative Commons license, and indicate if changes were made. 


\section{References}

1. Siegel RL, Miller KD, Jemal A (2018) Cancer statistics, 2018. CA Cancer J Clin 68(1):7-30

2. Morgentaler A, Traish AM (2009) Shifting the paradigm of testosterone and prostate cancer: the saturation model and the limits of androgen-dependent growth. Eur Urol 55(2):310-320

3. Huggins C, Hodges CV (2002) Studies on prostatic cancer: I. The effect of castration, of estrogen and of androgen injection on serum phosphatases in metastatic carcinoma of the prostate. 1941. J Urol. 168(1):9-12

4. NCCN Clinical Practice Guidelines in Oncology (NCCN Guidelines $^{\circledR}$ ). Prostate Cancer. Version 2.2018-March 8, 2018. http://NCCN.org. Accessed 5 Sep 2018

5. Tolis G, Ackman D, Stellos A, Mehta A, Labrie F, Fazekas AT et al (1982) Tumor growth inhibition in patients with prostatic carcinoma treated with luteinizing hormone-releasing hormone agonists. Proc Natl Acad Sci USA 79(5):1658-1662

6. Fujino M, Fukuda T, Shinagawa S, Kobayashi S, Yamazaki I (1974) Synthetic analogs of luteinizing hormone releasing hormone (LH-RH) substituted in position 6 and 10. Biochem Biophys Res Commun 60(1):406-413

7. Conn PM, Crowley WF Jr (1991) Gonadotropin-releasing hormone and its analogues. N Engl J Med 324(2):93-103

8. Crawford ED, Sartor O, Chu F, Perez R, Karlin G, Garrett JS (2006) A 12-month clinical study of LA-2585 (45.0 mg): a new 6-month subcutaneous delivery system for leuprolide acetate for the treatment of prostate cancer. J Urol. 175(2):533-536

9. Seidenfeld J, Samson DJ, Hasselblad V, Aronson N, Albertsen PC, Bennett CL et al (2000) Single-therapy androgen suppression in men with advanced prostate cancer: a systematic review and meta-analysis. Ann Intern Med 132(7):566-577
10. Lepor H, Shore ND (2012) LHRH agonists for the treatment of prostate cancer: 2012. Rev Urol. 14(1-2):1-12

11. Crook JM, O'Callaghan CJ, Duncan G, Dearnaley DP, Higano CS, Horwitz EM et al (2012) Intermittent androgen suppression for rising PSA level after radiotherapy. N Engl J Med 367(10):895-903

12. Hussain M, Tangen CM, Berry DL, Higano CS, Crawford ED, Liu $\mathrm{G}$ et al (2013) Intermittent versus continuous androgen deprivation in prostate cancer. N Engl J Med 368(14):1314-1325

13. Calais da Silva F, Calais da Silva FM, Goncalves F, Santos A, Kliment J, Whelan P et al (2014) Locally advanced and metastatic prostate cancer treated with intermittent androgen monotherapy or maximal androgen blockade: results from a randomised phase 3 study by the South European Uroncological Group. Eur Urol. 66(2):232-239

14. Lepor $\mathrm{H}$ (2005) Comparison of single-agent androgen suppression for advanced prostate cancer. Rev Urol. 7(Suppl 5):S3-S12

15. Eligard $^{\circledR}$ (Leuprolide acetate for injection). Product Monograph. http://products.sanofi.ca/en/eligard.pdf. Accessed 5 Sep 2018

16. Cornford P, Bellmunt J, Bolla M, Briers E, De Santis M, Gross T et al (2017) EAU-ESTRO-SIOG Guidelines on Prostate Cancer. Part II: treatment of relapsing, metastatic, and castration-resistant prostate cancer. Eur Urol. 71(4):630-642

17. Markman M (2011) Cross-trial comparisons in the oncology arena: when is this justified? Oncology. 80(3-4):151-152

18. Spitz A, Young JM, Larsen L, Mattia-Goldberg C, Donnelly J, Chwalisz K (2012) Efficacy and safety of leuprolide acetate 6-month depot for suppression of testosterone in patients with prostate cancer. Prostate Cancer Prostatic Dis 15(1):93-99

Publisher's Note Springer Nature remains neutral with regard to jurisdictional claims in published maps and institutional affiliations. 